\title{
Stability of context in sport and exercise across educational transitions in adolescence: hello work, goodbye sport club?
}

\author{
Vanessa Gut ${ }^{\dagger}$, Julia Schmid ${ }^{*}{ }^{-0}$, Lars Imbach and Achim Conzelmann
}

\begin{abstract}
Background: The present study firstly aimed to identify context patterns in sport and exercise among adolescents at lower and upper secondary education. The organisational, social and competitive contexts of leisure-time sport and exercise were included as pattern indicators. The second aim was to examine the stability of these patterns across educational transition. The last aim was to investigate whether a subjective evaluation of the transition influences whether people stay in the same pattern across time.
\end{abstract}

Methods: One-year longitudinal data of 392 adolescents were analysed.

Results: Both before and after the educational transition, four context patterns were identified: the traditional competitive club athletes with friends, the self-organised individualists, the non-club-organised sportspersons and the mostly inactives. More than half of the individuals stayed in the same pattern across time. When individuals changed pattern, their change was most often from the self-organised individualists and the non-club-organised to the mostly inactives. A subjective evaluation of the transition influenced the stability of only the traditional competitive club athletes with friends. The chance of these people staying in the same pattern decreased with increased transitional stress.

Conclusions: Knowledge about the stability and change of context patterns can be used to make recommendations for policy strategies and to develop more individually-tailored promotion programs.

Keywords: Physical activity, Youth, Person-oriented approach, Social-ecological framework, Life event

\section{Introduction}

The transition from lower to upper secondary education ${ }^{1}$, occurring between 14 and 16 years of age, can be a major life event for many adolescents. They are faced with different challenges, such as a changed environment, new social roles or higher academic demands [2]. Indeed, there is evidence that this educational transition

\footnotetext{
${ }^{1}$ The terms lower and upper secondary education refer to the international standard classification of education [1]. In many educational systems, the end of lower secondary education is the end of general, compulsory schooling. In contrast, upper secondary education typically prepares students more specifically for tertiary education or provides skills relevant for employment.
}

\section{*Correspondence: julia.schmid@unibe.ch}

†Vanessa Gut and Julia Schmid contributed equally to this work.

Institute of Sport Science, University of Bern, Bremgartenstrasse 145,

3012 Bern, CH, Switzerland influences the sport and exercise behaviour of these young people [3]. For instance, a nationally representative longitudinal study from the Netherlands revealed that sport and exercise frequency decreased by around $20 \%$ when an individual left compulsary school [4]. Considering the various health benefits of physical activity [ 5 , 6], it is vital to promote it among adolescents during their educational transition. However, to develop policy strategies and interventions, it is essential not only to identify factors that influence physical activity behaviour, but also to understand their interplay within each individual. In the present study, we concentrate on sport and exercise, two similar subsets of physical activity. Both are planned, structured, and performed during leisure time [7]. 
According to the social-ecological framework [8], an individual's activity levels are impacted by behavioural context. Hence, this paper focuses on the 1) organisational, 2) social and 3) competitive context of sport and exercise. The organisational context refers to the setting in which adolescents do their sport and exercise. For example, they can participate in club activities (hereinafter referred to as a club-organised context), which are typically characterised by regular training sessions, coupled with the expectation that club members will voluntarily help out with additional club activities [9]. Alternatively, adolescents can be physically active with a commercial provider (e.g., gym, dance studio; hereinafter referred to as a non-club-organised context). Such activities have a similar organisational structure, but fewer social obligations [9]. Finally, adolescents may take part in self-organised activities that are flexible in terms of time (e.g., in informal groups; hereinafter referred to as a self-organised setting). The social context refers to the people with whom adolescents do their sport and exercise, i.e. with their family, friends, strangers, or alone. The competitive context refers to the mode of an activity. Adolescents can engage in competitive environments, where two or more rivals vie against one another, or they can opt for more recreational exercises.

The social-ecological framework [8] is supported by empirical research which shows that the aforementioned contextual factors are associated with maintaining exercise and sport. Thus, doing sport and exercise in a club during the years of adolescence is positively linked with being persistently active later on in life [10-13]. In contrast, doing organised, non-club activities (e.g., gym, using facilities offered by municipalities and private companies) has been associated with dropout $[9,14]$. Furthermore, adolescents who do sport and exercise with peers are more likely to lead an active lifestyle in adulthood [15] because the underlying mechanisms, such as emotional and instrumental support or motivation that serve to promote adolescents' sport and exercise behaviour [16] are present. Finally, competitive sport activities in adolescence are seen to make a difference in maintaining sport and exercise [17]. Studies have also indicated sex differences for all of the aforementioned behavioural contexts. For example, boys are more likely to engage in club-organised, competitive activities than girls (e.g., [18]).

Since, the context factors are related to sport and exercise behaviour, the question arises whether these factors change during adolescence and young adulthood. There is empirical evidence that exercise and doing sport in clubs decreases with age [9, 10, 19]. Furthermore, competitive sports activities in a team or as an individual decline when entering in adulthood $[19,20]$. This observed move away from club-based, competitive activities towards a more self-organised setting may be explained by increased educational demands and thus an increased need for flexibility [21].

Although there is some knowledge about change in the context of sport and exercise during adolescence and young adulthood, further empirical research is indicated. An important issue for future research is the focus on typical context patterns in sport and exercise. Up to now, behavioural contexts have been studied mostly in isolation (e.g., [17]), ignoring the fact that they do, indeed, interact. For instance, adolescents are more likely to participate in competitions if they are in a club setting (e.g., [20]). Therefore, it is relevant to examine not only which behavioural context patterns exist, but also how stable they are over time. Person-oriented studies focus on such configurations, which show how contexts interact within an individual $[22,23]$. The majority of these studies, have a relatively narrow focus because their investigation of patterns is limited to an organisational context of sport and exercise and/or in activity types (e. g., [24-26]). In this research, however, five to six different patterns were often identified. On the one hand, there were the traditional patterns, characterised either by club-organised team activities or as activities undertaken by an individual athlete. In contrast, more recreational patterns revealed activities that were less formal in nature and not club-organised (e.g., running, fitness). A recent cross-sectional study by Gut et al. [27] took a broader perspective and identified the following four patterns in adolescents: mostly inactives, non-club-organised individualists, selforganised individualists and family sportspersons, and the traditional competitive club athletes with friends. However, it was not investigated how stable these patterns were over time. In the person-oriented approach, researchers are usually interested in the effect of stability, on both group and individual levels. On a group level, so-called structural stability is high if patterns before and after the educational transition are replicated in similar forms (i.e. indicator means of the behavioural context patterns are more or less the same). Individual stability, on the other hand, refers to course of development between behavioural context patterns. If the majority of individuals are shown to belong to the same pattern both before and after the transition, individual stability is given [28].

Prospective longitudinal studies focusing on the transition from lower to upper secondary education are an additional issue for further research. Although there are several studies with a life-course perspective (e.g., 9), less is known about how the context of sport and exercise is impacted by this particular educational transition. 
Of interest is not only how the objective characteristic of this life event influences the context of sport and exercise, but also the adolescents' subjective evaluation of the event. It is likely that the transition is not perceived in the same way by all individuals and this, in turn, may affect behaviour $[29,30]$. We can assume that individuals who evaluate the transition as stressful may be more prone to changing the context of their sport and exercise. In fact, existing research shows that when stress is high, people are more likely to engage in non-competitive sport and exercise activities, for example [31].

In light of these two research gaps, the present study examined the following research questions:

1. Which behavioural context patterns in sport and exercise among adolescents exist before and after transitioning from lower to upper secondary education?

We identified patterns from three organisational context factors (club-organised, non-club-organised, selforganised settings), participation in competitions, as well as four social context factors (doing sport and exercise with friends, family/partner, people one does not know, or alone). Due to the relatively sparse person-oriented research in this area [13,27], we did not expect a specific number of patterns. However, we hypothesised the existence of a "traditional" pattern, including club-organised competitive activities with friends [25, 27]. We then compared the detected patterns in terms of current sport and exercise behaviour, gender, and type of sport and exercise. In line with existing research, we expected individuals in "traditional" patterns to have a higher sport and exercise volume and to be more often boys [25]. In contrast, we had no a priori hypothesis regarding differences in type of sport and exercise.

2. How stable are the behavioural context patterns in sport and exercise across educational transition?

In this study, we examined stability firstly at a group level by focusing on the structural stability of context patterns. Secondly, we examined it at an individual level, by analysing how many people stay in the same pattern and how many people change patterns across educational transition. Since there is no longitudinal research on the stability of behavioural context patterns, we pursued an explorative approach with no prior assumption on this topic.

3. Are the associations between behavioural context patterns before and after transition moderated by the subjective evaluation of educational transition?
Based on theoretical considerations [30] and initial empirical evidence $[13,31]$, we expected the subjective evaluation of the life event to influence stability in behavioural context patterns. More specifically, we assumed that the higher the transitional stress, the more likely a change in the behavioural context pattern would occur.

Addressing these questions helps to effectively promote sport and exercise. If academics, practitioners and policymakers are informed about the behavioural context patterns and their development with age, they can use this knowledge to make recommendations for promotion strategies and to develop more individually-tailored programs.

\section{Methods}

\section{Participant recruitment and procedures}

In this longitudinal study, adolescents were recruited from 77 different school classes in Switzerland. The first data collection took place in spring $2016\left(t_{1}\right)$, when adolescents were in their $9^{\text {th }}$ and last year of the lower secondary school. The second data collection was conducted one year later in spring $2017\left(t_{2}\right)$, after these adolescents had switched to either vocational education and training (VET), a baccalaureate school or a transitional option. At $t_{1}$, adolescents filled out a paper-pencil questionnaire during school lessons under the supervision of one of the authors. Adolescents were asked to provide their postal and mail-contact information for a second survey. At $t_{2}$, adolescents were contacted with a link to an online questionnaire. Participants who filled out both surveys received a voucher for 15 CHF. From the 953 adolescents at $t_{1}, 392$ participated a second time. Students were excluded from the study if they had psychological or physical disabilities or were not proficient in German. Adolescents provided their informed written consent for the study. The ethics commission of the Faculty of Human Sciences of the University of Bern approved the study design and procedures.

\section{Participant characteristics and study dropout}

Characteristics of the sample are summarised in the Electronical Supplementary Material, see Table S1. Study dropout analyses were conducted to compare those who were eligible for the study but did not participate at $t_{2}$ (dropouts, $n=553,58.5 \%$ ) with those who completed both questionnaire assessments (completers, $n=392$, $41.5 \%$ ) in terms of context and socio-demographic variables. No differences were found for sport and exercise activity level (minutes per week) and all behavioural context variables. However, t-tests and Chi-square tests showed that the study dropout rate was lower for the older participants $\left(t(865.926)=-2.618, p_{\text {bonferroni- }}\right.$ corrected $=.045, d=0.089 ; 95 \%$ CI $[0.027,0.186])$, girls 
$\left(\chi^{2}(1)=15.541, p<.0005, \phi_{\text {corr }}=0.281,95 \%\right.$ CI [.225, $.353])$, Swiss $\left(\chi^{2}(1)=8.488, p=.004, \phi_{\text {corr }}=0.231,95 \%\right.$ CI $[.171, .299])$ and those with a B school-level $\left(\chi^{2}(1)\right.$ $=24.121, p<.0005, \phi_{\text {corr }}=0.317,95 \%$ CI $\left.[.264, .392]\right)$. As the reported effect sizes are rather small, the sample might be biased negligibly.

\section{Measures}

\section{Volume and type of sport and exercise}

Sport and exercise volume was measured at $t_{1}$ and $t_{2}$ with the BSA questionnaire [32]. Participants named a maximum of three sport and exercise activities they had regularly engaged in within the last four weeks. They indicated the frequency and duration per episode in minutes for each activity. Based on this information, an overall index value in "min per week" was calculated. In addition, the weekly time in different activity types was computed and transformed into percentage variables (e.g., of the 100 minutes of sport and exercise per week, 60 minutes were football and 40 minutes jogging, resulting in a percentage value of $60 \%$ for the first activity type and $40 \%$ for the second activity).

\section{Context of sport and exercise}

Right after the BSA questionnaire, adolescents were asked to choose their organisational context: Did they engage in the previously named sport and exercise activities (a) in a club, (b) a commercial provider, or (c) was it self-organised? They were also asked in which social context: Were they (a) alone, (b) with friends, (c) with family/partner or (d) with strangers? Furthermore, for each of the activities, the adolescents were asked if they participated in competitions. Afterwards, the weekly time in these different contexts was calculated (e.g., of the 100 min of sport and exercise per week, 60 min were done at the club and 40 minutes were self-organised) and converted into percentage variables (e.g., 60\% were done at the club and $40 \%$ were self-organised).

\section{Subjective evaluation of the educational transition}

The subjective evaluation of the educational transition was assessed at $t_{2}$ with a five-item inventory for lifechanging events $[33,34]$. Participants rated four aspects of the transition on a 5-point-likert-scale ranging from 1 (not true) to 5 (totally true): uncontrollability (e.g., "at first I was completely at the mercy of the event"), unpredictability (e.g., "the event was unpredictable for me"), impact (e.g., "the event forced me to plan my everyday life differently") and centrality (e.g., "the event hit me at my very core"). The internal consistency of the inventory was $\operatorname{good}(\alpha=0.75)$.

\section{Statistical analyses}

To identify context patterns in sport and exercise among adolescents in lower and upper secondary school
(Research question [RQ] 1), latent transition analysis was conducted [35]. All analyses were run in Mplus Version 8.0 [36] using maximum likelihood estimation with robust standard errors (MLR). For six adolescents it was not possible to calculate the targeted percentage value (0.31\% missing data). The missing data were accommodated via full-information maximum likelihood (FIML). In the first step, two to six context patterns were separately calculated for each measurement time using eight context factors. To decide the optimal number of context patterns, statistical and content-related criteria were considered. As statistical criteria, the Bayesian information criterion (BIC), sample-adjusted BIC, and the Bootstrapped likelihood-ratio test (BLRT) were used. The elbow-criterion was applied for BIC and sample-adjusted BIC [37]. In addition, content-related criteria, such as the principle of parsimony, conformity with theoretical considerations and interpretability were applied. Z-Scores were utilised to better interpret and label the patterns. To further validate the identified patterns, sport and exercise activity level, gender distribution, and type of sport and exercise activity were described and differences in these factors investigated with Wald-tests [38]. Structural stability of the patterns (RQ 2a) was examined with a measurement invariance test [37]. To investigate individual stability (RQ 2b), transition probabilities were calculated. To examine the overall moderation effect of a subjective evaluation of the transition on associations between the context patterns (RQ 3), a likelihood-ratio chi-square-test was conducted [39]. A model with free slopes for the subjective evaluation (interaction model) was compared with a model with slopes fixed at 0 (no interaction model). Additionally, a multinominal logistic regression analysis was performed on a latent level. This follow-up analysis allows interaction effects to be investigated in more detail (e.g., which specific pattern has an interaction effect and which does not).

\section{Results}

\section{Behavioural context patterns in sport and exercise}

For both measurement points, two- to eight-pattern-solutions were tested. In general, BIC and sample-adjusted BIC improved with more patterns (see Electronical Supplementary Material, Table S2). BLRTs were significant for all pattern solutions. The elbow-criterion pointed to a three- to five-pattern model. However, in the five-pattern solutions, convergence problems occurred when conducting latent transition analysis. A closer inspection of the content-related indicators revealed the four-pattern solutions as the most favoured model for both $t_{1}$ and $t_{2}$ (see Tables 1 and 2). In the three-pattern solutions, patterns varied only in organisational context factors and 
thus were considered to fail to adequately differentiate. The four-pattern solution for $t_{1}$ and $t_{2}$ consists of the following behavioural context patterns: (1) traditional competitive club athletes with friends, (2) self-organised individualists, (3) non-club-organised sportspersons and (3) mostly inactives.

The traditional competitive club athletes with friends make up the largest pattern $\left(t_{1}: n=179 ; 45.66 \% ; t_{2}: n=\right.$ $152,38.78 \%)$. They are characterised by doing sport and exercise with friends in a club and participating in competitions. Compared to the overall sample, there is an above average number of young males in this pattern $\left(t_{1}: 49.10 \%, t_{2}: 42.40 \%\right)$. The traditional competitive club athletes with friends are the most active $\left(t_{1}: 318.98 \mathrm{~min}\right.$ sport and exercise/week, $t_{2}: 297 \mathrm{~min}$ sport and exercise/ week). They practise primarily sports games $\left(t_{1}: 68.50 \%\right.$, $t_{2}$ : 66.90\%; see Electronical Supplementary Material, Table S3). The self-organised individualists $\left(t_{1}: n=81\right.$, $\left.20.66 \% ; t_{2}: 68,17.35 \%\right)$ often do sport and exercise in a self-organised context and are mainly active alone, compared to the other adolescents. $63.80 \%\left(t_{1}\right)$ and $60.30 \%$ $\left(t_{2}\right)$ respectively were females. Adolescents in this pattern are relatively active $\left(t_{1}: 247.90 \mathrm{~min}, t_{2}: 218.00 \mathrm{~min}\right.$ sport and exercise/week). While many carry out fitness $(23.60 \%)$ or sports games $(27.80 \%)$ at $t_{1}$, the percentage values shift slightly at $t_{2}$ (fitness: $32.30 \%$ vs. sports games: $18.50 \%)$. The non-club-organised sportspersons $\left(t_{1}\right.$ and $\left.t_{2}: n=51 ; 13.01 \%\right)$ do their sport and exercise mainly in a non-club-organised setting, such as a gym or a dance studio. This pattern has the highest percentage of females $\left(t_{1}: 82.20 \%, t_{2}: 69.20 \%\right)$. The non-club-organised sportspersons are relatively active, with $247.01 \mathrm{~min}\left(t_{1}\right)$ and $278.73 \mathrm{~min}\left(t_{2}\right)$ of sport and exercise per week. At $t_{1}$, they practise compositional-creative activities mainly, such as dancing (44.40\%) and fitness (22.20\%). At $t_{2}$, the weekly volume of fitness activities increases (46.90\%), while that of compositional-creative activities decreases (26.50\%). The mostly inactives $\left(t_{1}: n=81,20.66 \% ; t_{2}: 121,30.87 \%\right)$ do no sport and exercise or only a little $\left(t_{1}: 51.51 \mathrm{~min}, t_{2}\right.$ : $23.33 \mathrm{~min}$ sport and exercise/week). Consequently, they have average to under-average $\mathrm{z}$-values in all context factors. In this pattern, $70.70 \%\left(t_{1}\right)$ and $66.20 \%\left(t_{2}\right)$ are females. If they are active, they practise mainly sports games $(24.80 \%)$ and relaxation-oriented activities, which lower energetic arousal, such as yoga or tai chi $(21.20 \%)$ at $t_{1}$. Only the proportion of the sports games remains stable at $47.10 \%$ at $t_{2}$.

\section{Structural and individual stability of the context patterns across educational transition}

The structural measurement invariance testing $\left(x^{2}=\right.$ 29.90, $p=.57$ ) indicates that patterns are stable over time and can be interpreted in the same way before and after educational transition. Overall, $58.20 \%(n=228)$ of all adolescents stay in the same context pattern over time. However, the transition probabilities in Fig. 1 show that the percentages vary between patterns. The traditional competitive club athletes with friends $(66.40 \%)$ and the mostly inactives $(65.30 \%)$ most often remain in the same pattern. In contrast, the proportion of remainers is smaller in the self-organised individualists $(41.20 \%)$ and the non-club-organised sportspersons (41.20\%). Some people in these two patterns switch to the mostly inactives after educational transition $(31.50 \%$ and $27.60 \%$, respectively).

The moderating effect of a subjective evaluation of the transition on stability in behavioural context patterns

The likelihood-ratio chi-square-test revealed an overall moderation effect of a subjective evaluation $\left(\mathrm{x}^{2}[d f=15]\right.$ $=23.24, p=.0791$ ). Table 3 reports the findings of the multinominal logistic regression analysis for each pattern, whereby the mostly inactives served as a reference group. Results showed that the competitive club athletes were less likely to be in the same pattern after the educational transition when they perceived the transition as stressful $(B=-0.781$ [CI 95\%: -1.317, -0.246], $p=.004)$.

\section{Discussion}

In the present study, behavioural context patterns in exercise and sport were identified and their stability across educational transitions examined. Furthermore, it was tested whether associations between patterns over time are moderated by a subjective evaluation of educational transition.

Both before and after the educational transition, four behavioural context patterns were identified: (1) the traditional competitive club athletes with friends, (2) the self-organised individualists, (2) the non-club-organised sportspersons and (3) the mostly inactives. The patterns found are very similar to those identified by Gut et al. [27]. As hypothesised, the first pattern has a "traditional" character, as individuals doing sport and exercise with friends in a club and participating in competitions. The fact that this pattern consists of a relatively high number of males as well as active adolescents is also consistent with our hypothesis. An explanation for the high level of activity can be seen in the fact that competitive sport requires regular club training sessions [25]. It is not surprising that this pattern is the largest one, as previous variable-oriented [40] and person-oriented studies [27] show that the most popular context for adolescents is doing activities in clubs and with friends. The second and third patterns are smaller and characterised by more informal, flexible and non-competitive exercise contexts. The fact that the non-club-organised sportspersons have 


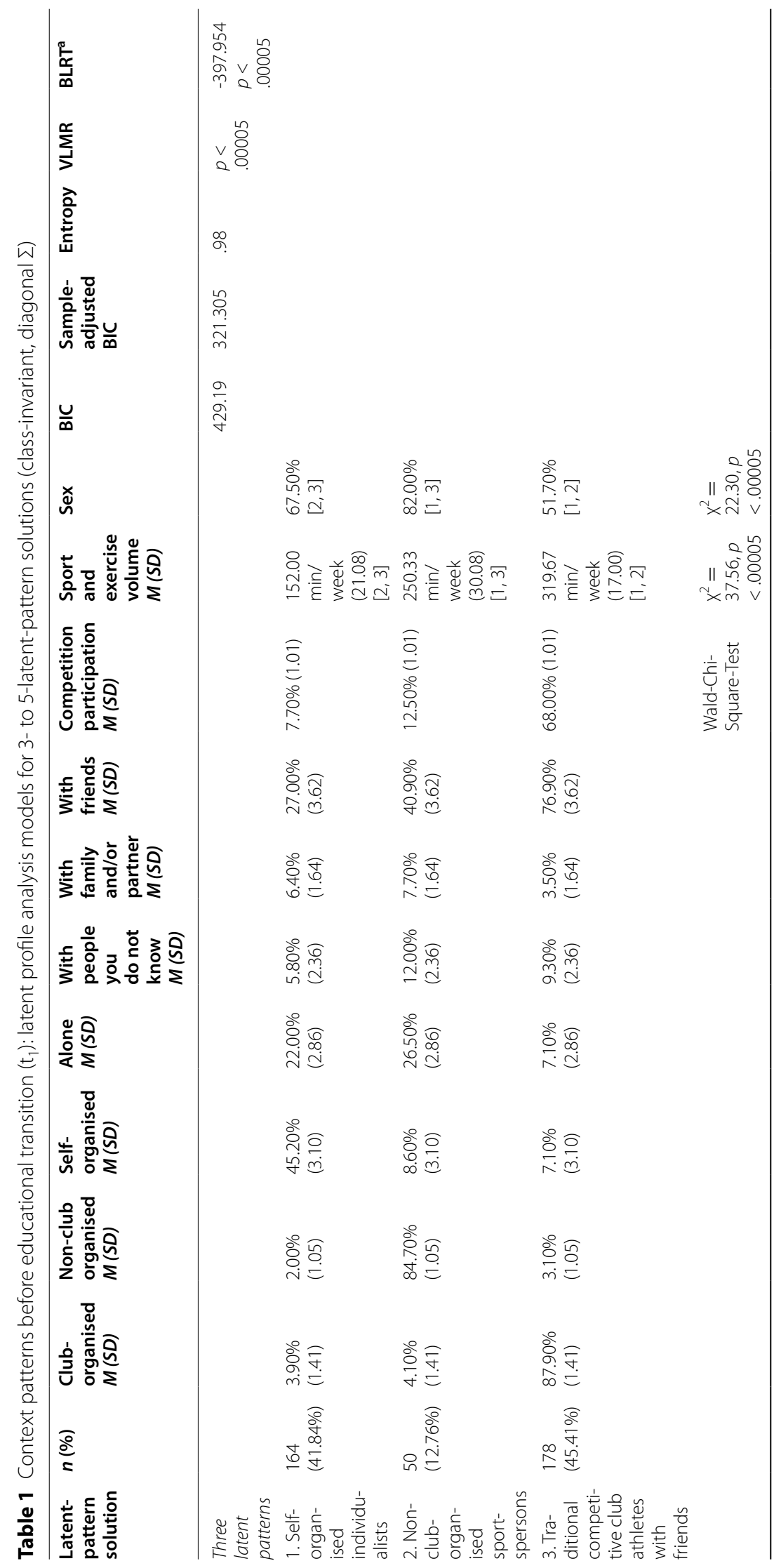




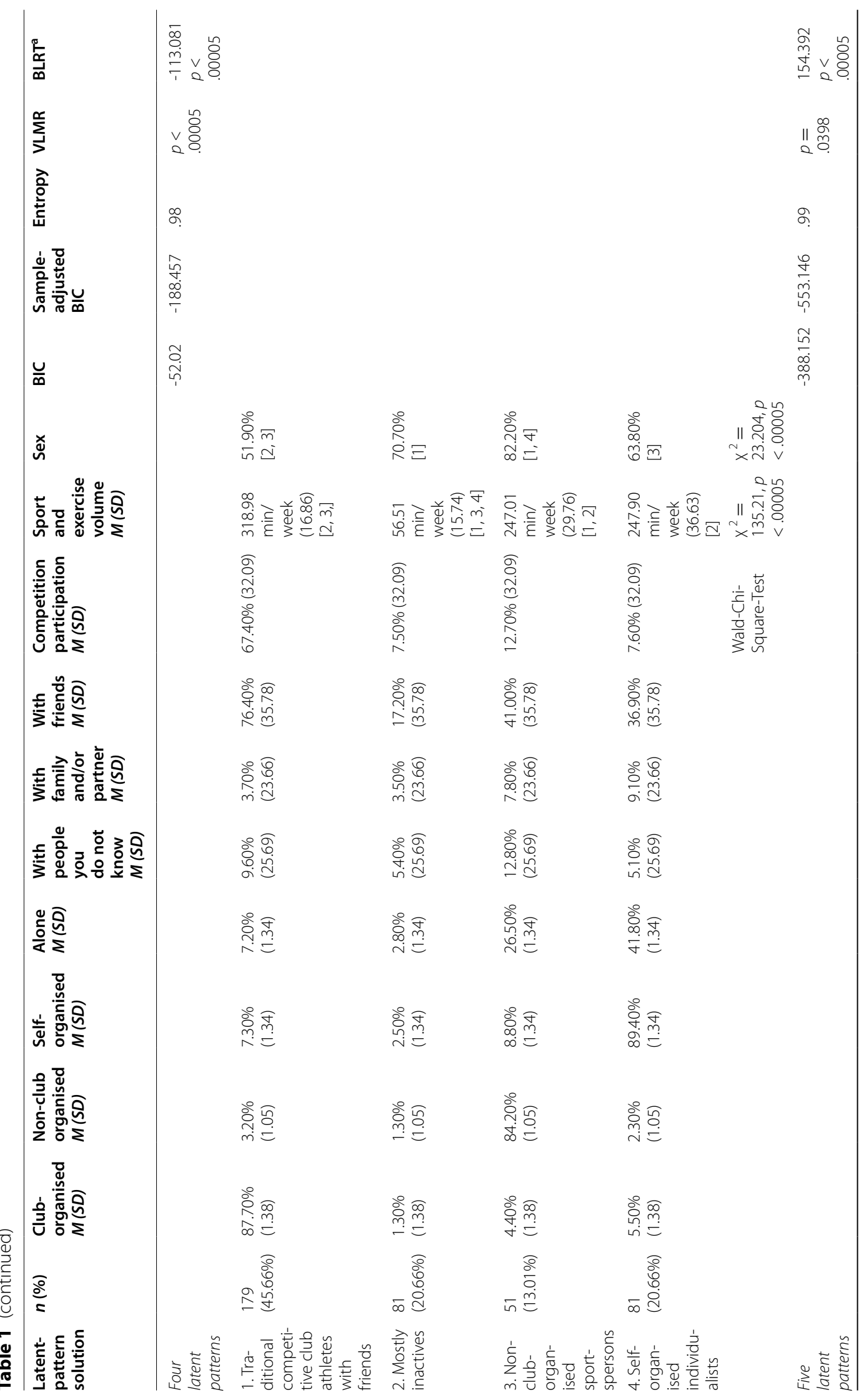




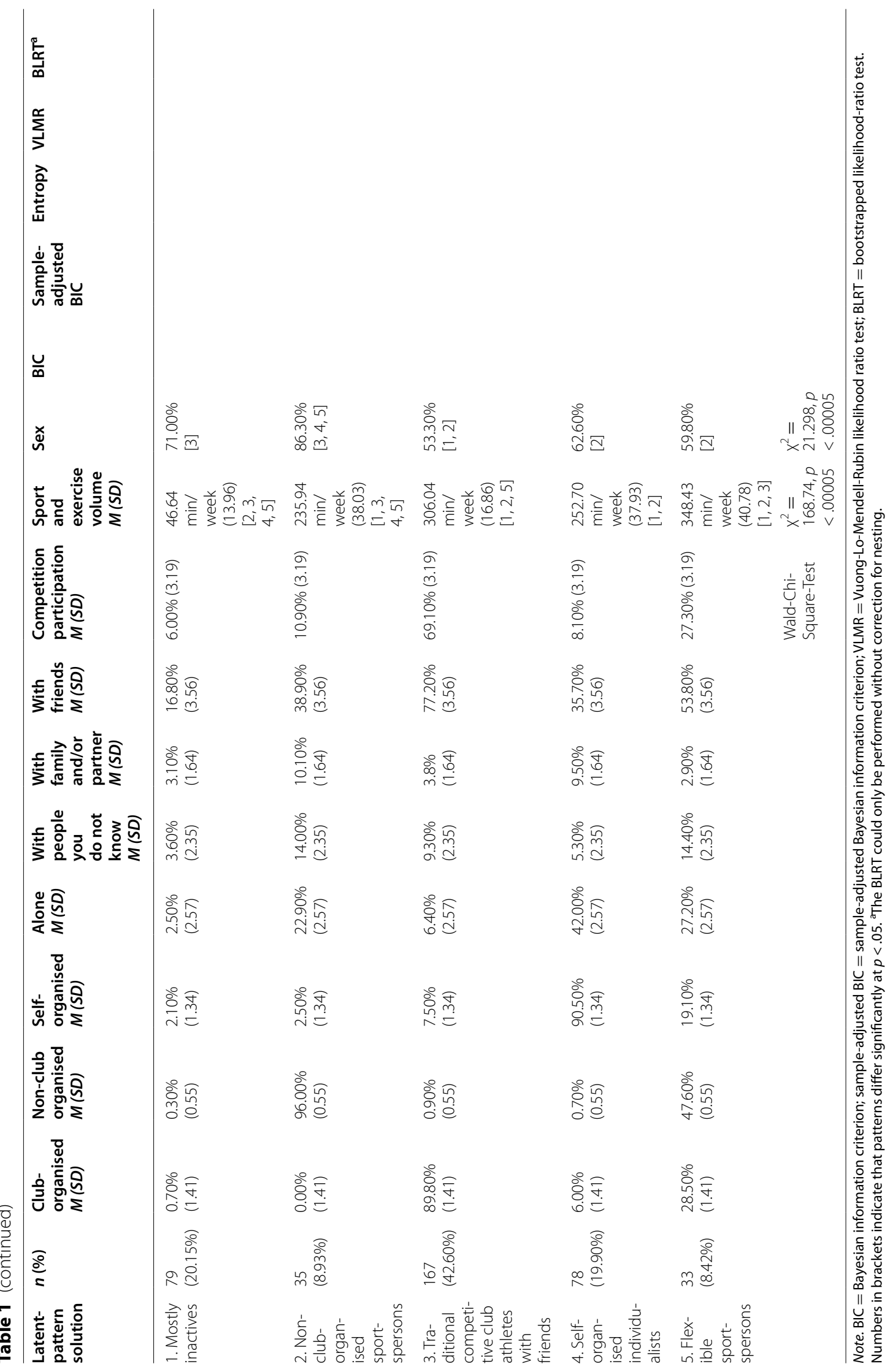




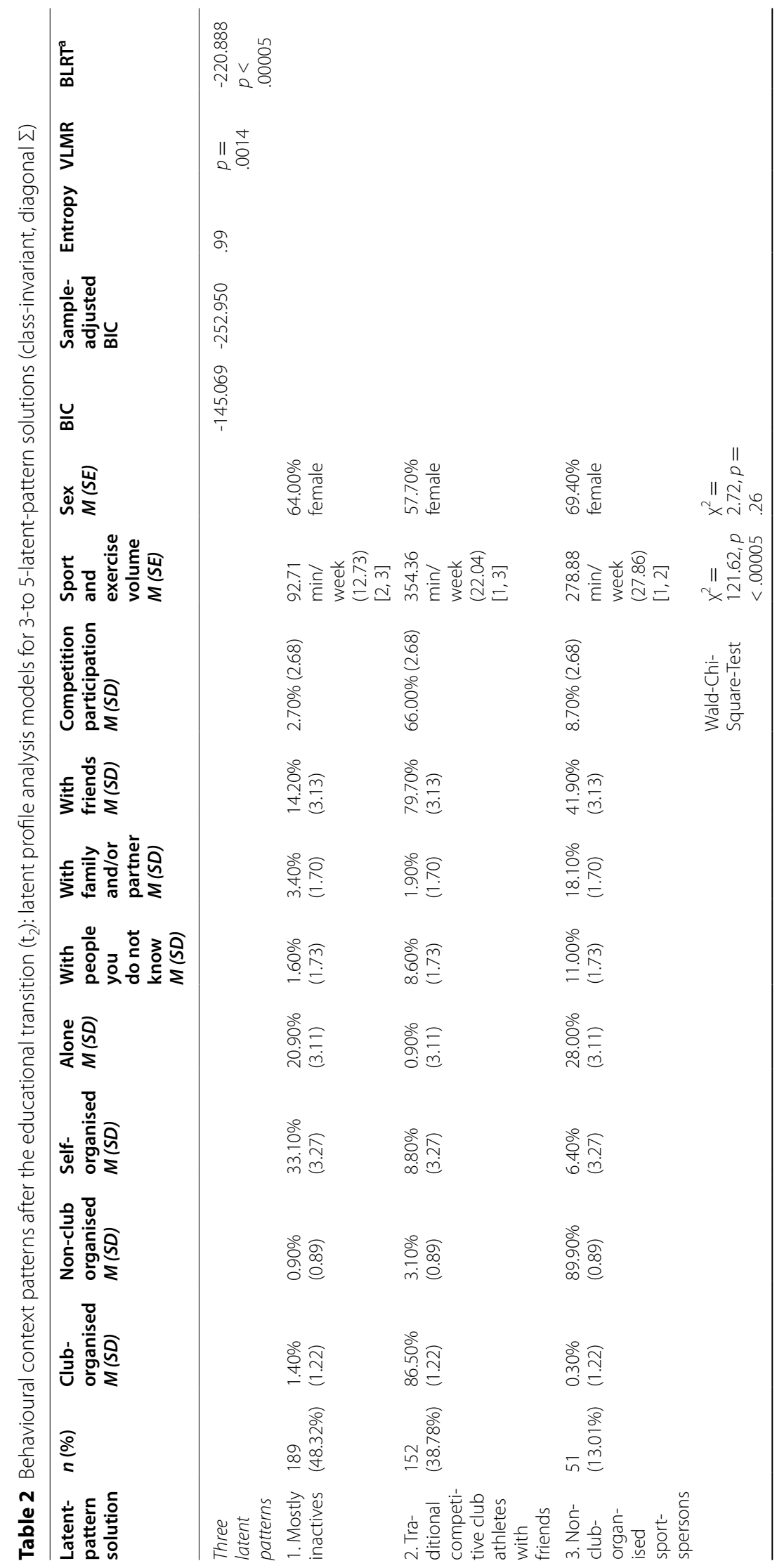


Gut et al. BMC Public Health $\quad$ (2022) 22:152

Page 10 of 15

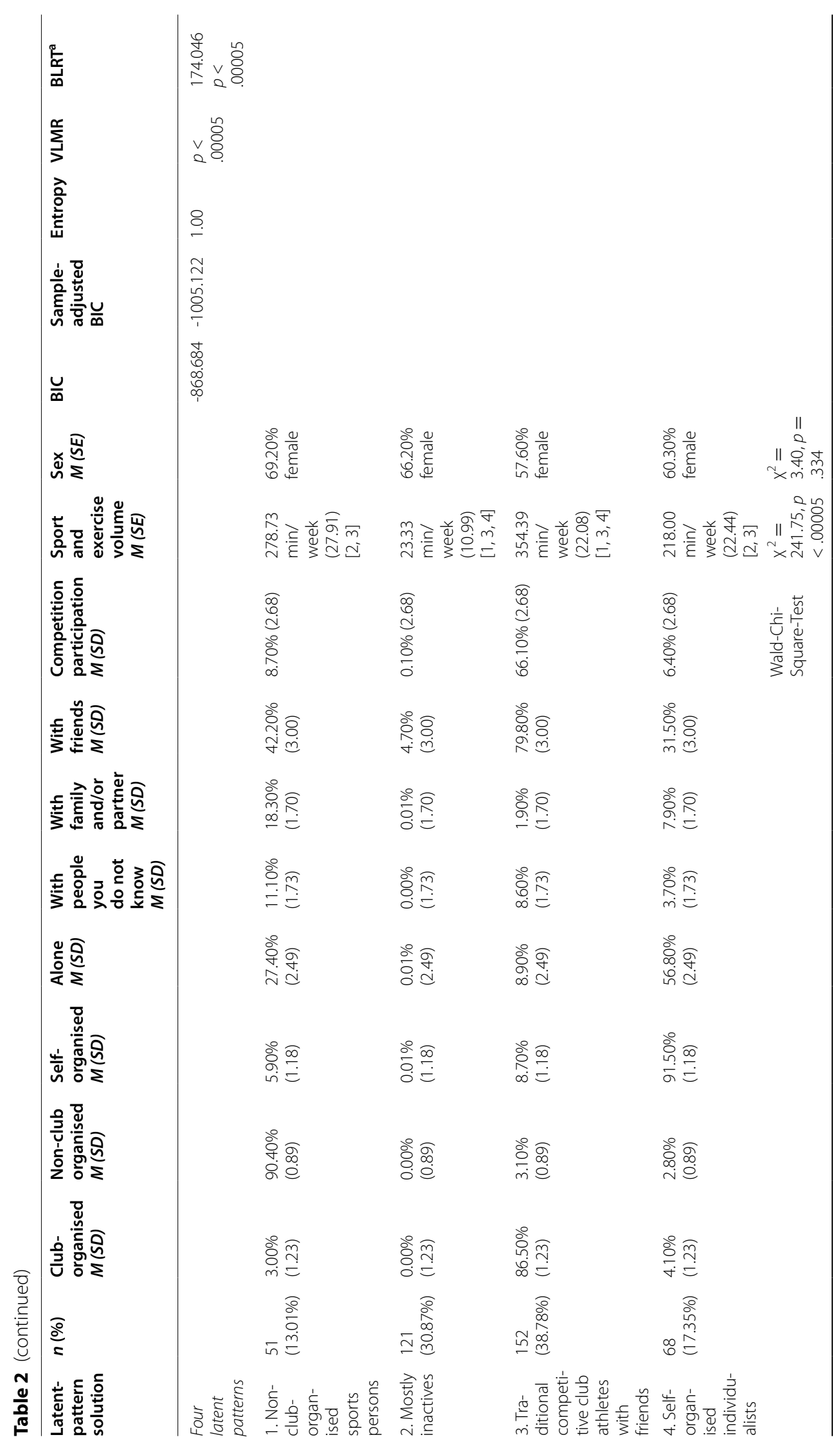




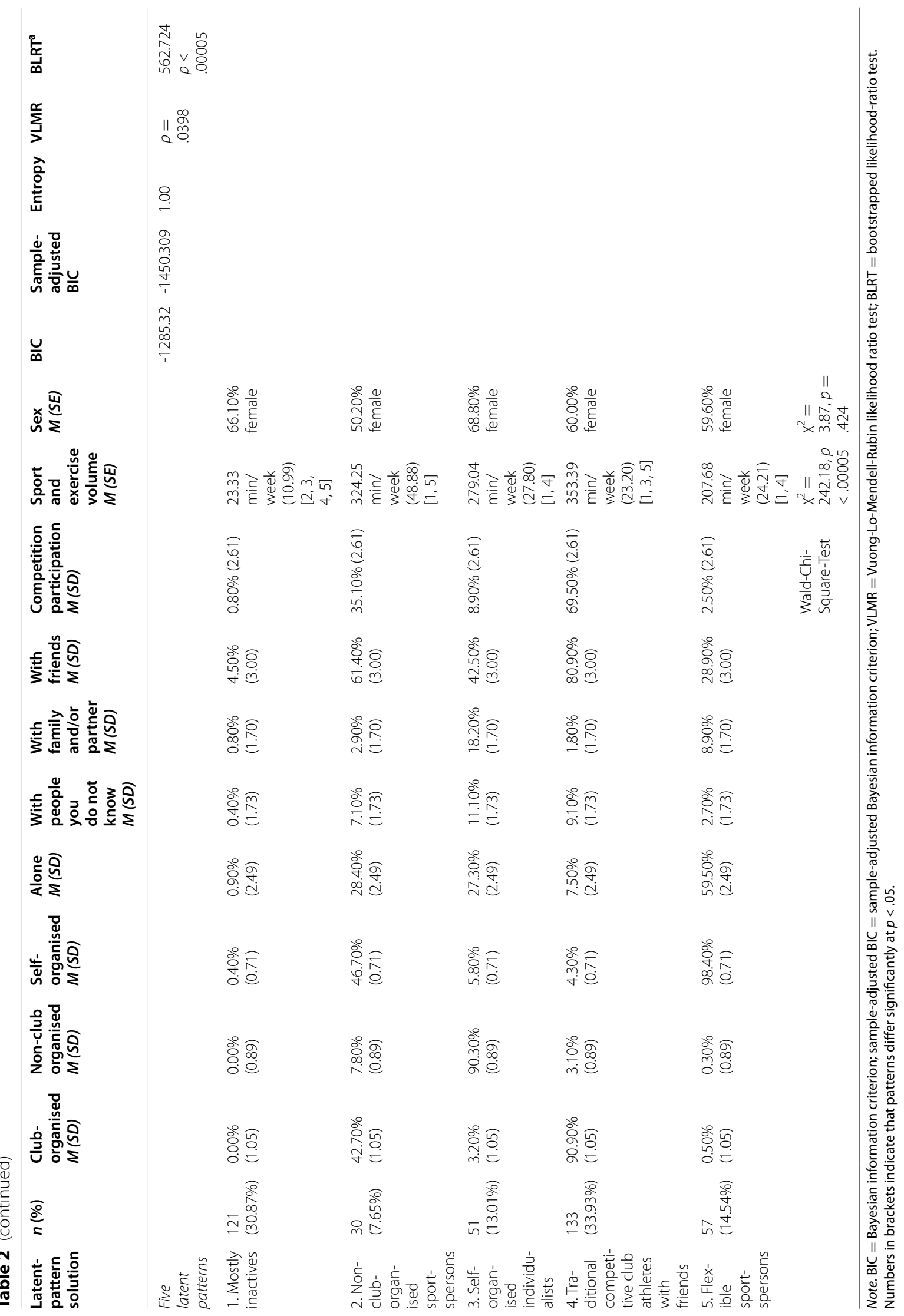




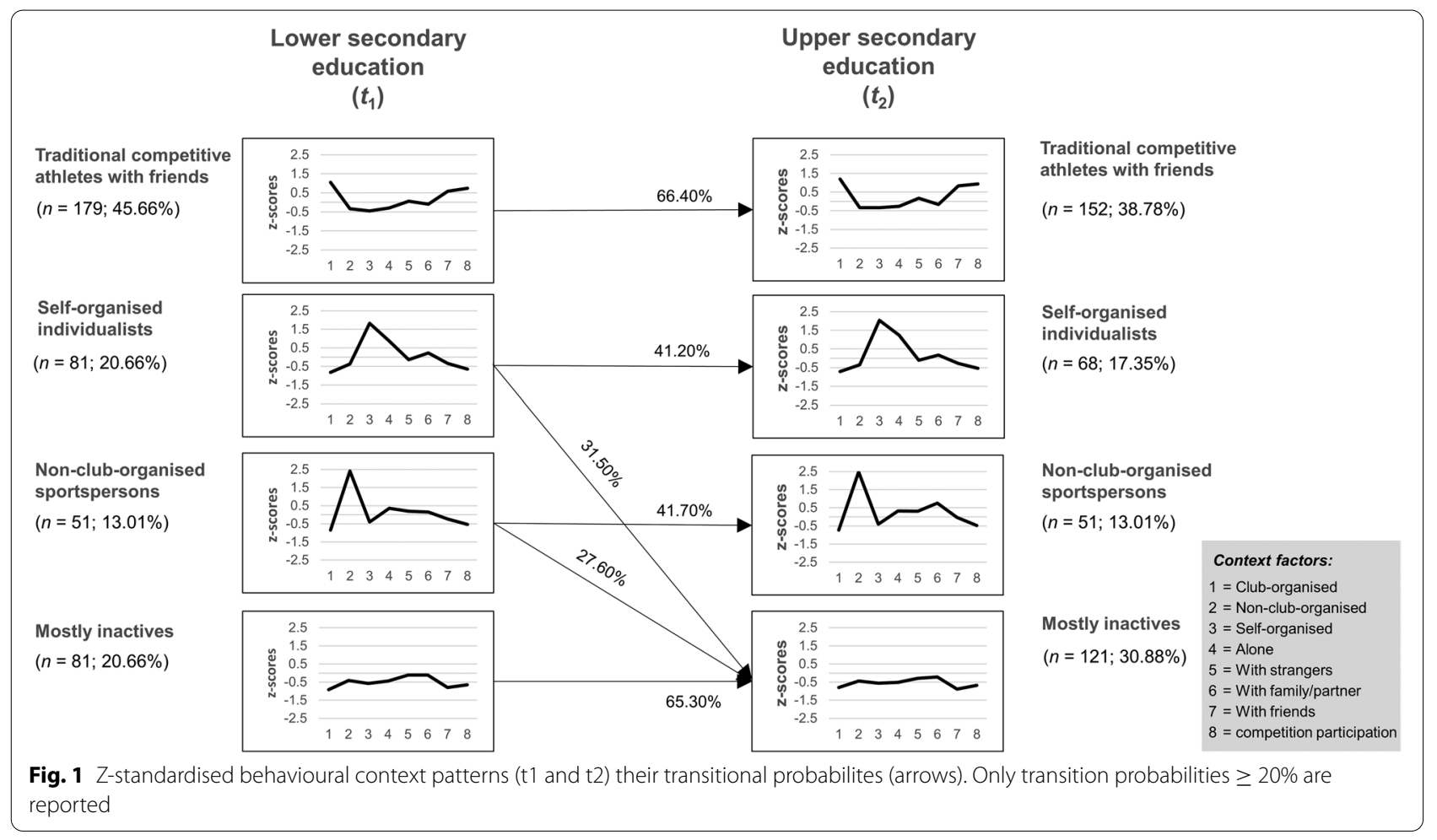

Table 3 The moderating effects of a subjective evaluation of the educational transition on the associations of context patterns

\begin{tabular}{|c|c|c|c|c|c|c|c|c|}
\hline & \multicolumn{8}{|c|}{ Upper secondary education $\left(t_{2}\right)$} \\
\hline & \multicolumn{2}{|c|}{$\begin{array}{l}\text { Traditional competitive club } \\
\text { athletes with friends }\end{array}$} & \multicolumn{2}{|l|}{$\begin{array}{l}\text { Non-club-organised } \\
\text { sportspersons }\end{array}$} & \multicolumn{2}{|l|}{$\begin{array}{l}\text { Self-organised } \\
\text { individualists }\end{array}$} & \multicolumn{2}{|c|}{ Mostly inactives } \\
\hline & $B[95 \% \mathrm{Cl}]$ & $p$-value & $B[95 \% \mathrm{Cl}]$ & $p$-value & $B[95 \% \mathrm{Cl}]$ & $p$-value & $B[95 \% \mathrm{Cl}]$ & $p$-value \\
\hline \multicolumn{9}{|l|}{ Lower secondary education $\left(t_{1}\right)$} \\
\hline $\begin{array}{l}\text { Traditional competitive club } \\
\text { athletes with friends } \times \text { subjec- } \\
\text { tive evaluation }\end{array}$ & $-0.781[-1.317,-0.246]$ & $.004^{*}$ & $-0.402[-1.052,0.248]$ & .225 & $-0.50[-1.187,0.184]$ & .152 & - & - \\
\hline $\begin{array}{l}\text { Non-club-organised sportsper- } \\
\text { sons } x \text { subjective evaluation }\end{array}$ & $0.243[-0.280,1.165]$ & .614 & $-0.453[-0.325,1.397]$ & .239 & $0.056[-0.563,0.841]$ & .886 & - & - \\
\hline $\begin{array}{l}\text { Self-organised individualists x } \\
\text { subjective evaluation }\end{array}$ & $0.443[-0.280,1.165]$ & .230 & $0.536[-0.325,1.397]$ & .222 & $0.139[-0.563,0.841]$ & .698 & - & - \\
\hline $\begin{array}{l}\text { Mostly inactives } x \text { subjective } \\
\text { evaluation }\end{array}$ & $-0.149[-0.855,0.556]$ & .678 & $-0.062[-0.772,0.648]$ & .864 & $0.304[-0.486,1.094]$ & .451 & - & - \\
\hline
\end{tabular}

Note. For the analyses of the main effects of the psychosocial profiles, one-sided significance tests were applied. $B=$ unstandardised B-regression coefficient; ${ }^{*} p<$ $.05 . \mathrm{Cl}=$ confidence interval for unstandardised B-regression coefficient. Reference groups: Mostly inactives. For the moderation analysis, two-sided significance tests were applied.

the highest number of females is in line with previous research, which highlights that female adolescents often favour commercial providers, such as a gym or a dance studio [19].

The identified behavioural context patterns are structurally stable across educational transition, meaning that they were very similar on a group level. Analysis on the individual level overall showed that around 60\% of the adolescents stayed in the same behaviour context patterns, whereas around $40 \%$ moved to another pattern. However, a closer look at the results reveals that the likelihood of remaining in the same behaviour context pattern differs between patterns. The competitive club athletes with friends had the highest probability of 
remaining in the same highly active pattern, while that of the self-organised individualists and the non-club-organised sportspersons was much lower. Individuals of the latter two patterns often changed to the mostly inactives (see Fig. 1). To sum up, it seems that doing sport and exercise in a context with few social and organisational obligations during lower secondary education increases the risk of dropping out altogether from sport and exercise. In contrast, the sport clubs, with their regular training sessions and friends as a source of social support, may be factors beneficial for staying active across educational transition $[12,15]$.

As assumed, moderation analysis revealed overall that a subjective evaluation of the transition influenced the stability of behavioural context patterns across time. In more differentiated analyses, however, the moderation effect could be demonstrated for only one behaviour context pattern: the traditional competitive club athletes with friends. The chance of those people staying in the same pattern decreased with increased transitional stress. These findings illustrate that the objective characteristics of a life event and its subjective evaluation could have distinct impacts on stability and change of sport and exercise context [41, 42]. It is important to consider both aspects simultaneously as it provides a greater understanding of the mechanism [30]. However, the question arises as to why the traditional competitive club athletes with friends in particular are influenced by transitional stress. One of the characteristics of perceived high stress is that adolescents are forced to organise their everyday life differently or need to adapt their usual activities [33]. It can therefore be speculated that club training sessions with relatively fixed training times and places [9] were no longer compatible with the new life situation. Furthermore, competitive sport and exercise activities are often time-consuming and therefore difficult to maintain for adolescents with limited resources during stressful educational transitions [31]. In contrast, the self-organised individualists and the non-club-organised sportspersons may have already been strongly influenced by the objective characteristics of the life event and the perceived transitional stress did not have an additional effect on their sport and exercise context.

\section{Strengths, limitations and future directions}

A strength of the present study is its focus on typical patterns. Whereas existing research has examined isolated context factors, the present research looked at the interplays of organisational, social and competitive factors within a person. Furthermore, this study adds value by its prospective longitudinal design and by the simultaneous consideration of an objective life event and the perception of transitional stress. The closer look at the transition from lower to upper secondary education seems to be particularly important because many adolescents decrease their amount of sport and exercise during this period [15]. However, we acknowledge some limitations. Firstly, the dropout analysis showed that the longitudinal study sample was distorted. Individuals were more likely to participate at both measurement points if they were older, girls, Swiss, and had reached B schoollevel. Such a self-selection runs the risk of rendering the sample no longer representative of the whole population of adolescents born between 2000 and 2001. However, one should keep in mind that the effect sizes were rather small and, therefore, may have affected our findings only marginally. Further, it is to be emphasised that the response rate (42\%) was high compared to other longitudinal studies with youths [20]. Secondly, the diverse behaviour context factors were not included in the analyses in a balanced way (organisational context: four factors, social context: three factors, competitive context: one factor). Consequently, for instance, the organisational context had much more weight in the LTA, in relation to the competitive context [43]. It cannot be ruled out that this influenced the results of the present research. Thirdly, this study consists of only two measurement time points, one year apart. Although the longitudinal design already extends existing, mostly cross-sectional studies (e.g., [24, 27]), future studies should follow adolescents longer and interview them at multiple time points. With such a design, for example, it would be possible to study how a change in behaviour context pattern is associated with a change in sport and exercise volume or in health. Fourthly, the sample in the present study consisted of adolescents with diverse educational transitions (see Supplementary material, Table S1). The large majority of young people switched from lower secondary education to VET (61\%). However, there were also individuals who changed from lower secondary education to baccalaureate school (28\%) or transitional options (11\%). It is possible that the type of transition experienced influenced the chance to stay in the same behaviour context pattern across time. Finally, to a certain extent, it remains unclear which factors boost change in behaviour context patterns and which protect against change. Although we were able to show that a subjective evaluation of the transition moderates individual stability [34], more in-depth studies using qualitative research methods would be interesting [44]. For instance, it can be assumed that psychological determinants play a protective role. Indeed, recent studies show that combining sport and exercise in a club with the individual's ability to plan activities boosts the chances of staying active across educational transition 
[10-13]. Furthermore, it is conceivable that financial ressources influence individual stability of behaviour context patterns, because, for example, a sport club membership is typically less expensive in Switzerland than regular training in a gym. In line with the basic idea of the socialecological framework [8], promotional measures should, therefore, be applied simultaneously at both the individual level (e.g., promotion of an individual's volition) and the structural level (e.g., promotion of facility and access to sport clubs).

\section{Conclusion}

The four behaviour context patterns found differ in their organisational, social and competitive settings of exercise and sport. More than half of the adolescents remained in the same pattern across their educational transition. Individuals, in particular, who did competitive sport with friends in a club during their lower secondary education are very likely to continue to do so. However, if these adolescents perceived high transitional stress, they often changed the context of sport and exercise and consequently said "goodbye" to their sport club.

The present study helps to better understand stability and changes in the context of sport and exercise behaviour, which is important for effectively promoting sport and exercise during the transition from lower to upper secondary education. Thus, the identified patterns can be used to develop policy strategies (e.g., promoting club-organised sport and exercise activities with regular training sessions and friends before educational transitions) and tailored interventions for specific subgroups of young people (e.g., empower the traditional competitive club athletes with friends to cope with transitional stress).

\section{Abbreviations \\ BIC: Bayesian information criterion; BLRT: Bootstrapped likelihood-ratio test; MLR: Maximum likelihood estimation with robust standard errors; RQ: Research question; VET: Vocational education and training.}

\section{Supplementary Information}

The online version contains supplementary material available at https://doi. org/10.1186/s12889-021-12471-4.

\section{Additional file 1.}

Additional file 2 .

Additional file 3.

\section{Authors' contributions}

JS and AC contributed to the conception and design of the study. VG and JS acquired the data. VG and LI performed statistical analysis. JS wrote and drafted the manuscript. JS, VG and LI contributed to data analysis and interpretation. JS, AC, VG and LI critically reviewed initial versions of the manuscript. All authors revised the manuscript critically for important intellectual content, as well as read and approved the final manuscript.

\section{Funding}

The study was supported by a grant from the Suzanne and Hans Biäsch foundation for the promotion of applied psychology (grant number: 2016/28). The funder had no role in study design, data collection and analysis, decision to publish, or preparation of the manuscript.

\section{Availability of data and materials}

The datasets and syntaxes used during the current study are available from the corresponding author on request.

\section{Declarations}

\section{Ethics approval and consent to participate}

All participants gave their written informed consent and were free to decline participation. Additionally, adolescents under 16 years of age required written confirmation from their legal guardians to participate. Furthermore, we confirm that we carried out all methods of this study in accordance with relevant guidelines and regulations. The Ethics Committee of the University of Bern's Faculty of Human Sciences approved the all the methods of the study.

\section{Consent for publication}

Not applicable.

\section{Competing interests}

The authors declare that they have no competing interests.

Received: 16 March 2021 Accepted: 23 December 2021

Published online: 21 January 2022

\section{References}

1. UNESCO Institute of Statistics. International Standard Classification of Education: ISCED 2011. Quebec: Montreal; 2012.

2. Miller TW. Life stress and transition in the life span. In: Miller TW, editor. Handbook of stressful transitions across the lifespan. New York, NY: Springer; 2010. p. 3-17.

3. Gropper H, John JM, Sudeck G, Thiel A. The impact of life events and transitions on physical activity: a scoping review. PLOS ONE. 2020;15:e0234794. https://doi.org/10.1371/journal.pone.0234794.

4. van Houten JMA, Kraaykamp G, Pelzer BJ. The transition to adulthood: a game changer!? A longitudinal analysis of the impact of five major life events on sport participation. European Journal for Sport and Society. 2019;16:44-63. https://doi.org/10.1080/16138171.2019.1603832.

5. Warburton DER, Bredin SSD. Health benefits of physical activity: a systematic review of current systematic reviews. Curr Opin Cardiol. 2017;32:54156. https://doi.org/10.1097/HCO.0000000000000437.

6. Beauchamp MR, Puterman E, Lubans DR. Physical inactivity and mental health in late adolescence. JAMA Psychiatry. 2018;75:543-4. https://doi. org/10.1001/jamapsychiatry.2018.0385.

7. Strath SJ, Kaminsky LA, Ainsworth BE, Ekelund U, Freedson PS, Gary RA, et al. Guide to the assessment of physical activity: Clinical and research applications. A scientific statement from the American Heart Association. Circulation. 2013;128:2259-79. https://doi.org/10.1161/01.cir.0000435708. 67487.da.

8. Sallis JF, Cervero RB, Ascher W, Henderson KA, Kraft MK, Kerr J. An ecological approach to creating active living communities. Annu Rev Public Health. 2006;27:297-322. https://doi.org/10.1146/annurev.publhealth.27. 021405.102100 .

9. Borgers J, Vanreusel B, Lefevre J, Scheerder J. Involvement in non-club organized sport: Organizational patterns of sport participation from a longitudinal life course perspective. European Journal for Sport and Society. 2018;15:58-77. https://doi.org/10.1080/16138171.2018.1438079.

10. Zimmermann-Sloutskis D, Wanner M, Zimmermann E, Martin BW. Physical activity levels and determinants of change in young adults: a longitudinal panel study. International Journal of Behavioral Nutrition and Physical Activity. 2010. https://doi.org/10.1186/1479-5868-7-2.

11. Wichstrøm $L$, von Soest $T$, Kvalem IL. Predictors of growth and decline in leisure time physical activity from adolescence to adulthood. Health Psychol. 2013;32:775-84. https://doi.org/10.1037/a0029465. 
12. Simons D, Rosenberg M, Salmon J, Knuiman M, Granich J, Deforche B, et al. Psychosocial moderators of associations between life events and changes in physical activity after leaving high school. Preventive Medicine. 2015;72:30-3. https://doi.org/10.1016/j.ypmed.2014.12.039.

13. Schmid J, Gut V, Yanagida T, Conzelmann A. Who stays on? The link between psychosocial patterns and changes in exercise and sport behaviour when adolescents make transitions in education. Appl Psychol Health Well Being. 2020;12:312-34. https://doi.org/10.1111/aphw.12186.

14. Borgers J, Pilgaard M, Vanreusel B, Scheerder J. Can we consider changes in sports participation as institutional change? A conceptual framework. International Review for the Sociology of Sport. 2016;53:84-100. https:// doi.org/10.1177/1012690216639598.

15. Li K, Liu D, Haynie D, Gee B, Chaurasia A, Seo D-C, et al. Individual, social, and environmental influences on the transitions in physical activity among emerging adults. BMC Public Health. 2016;16:682. https://doi.org/ 10.1186/s12889-016-3368-3.

16. Deforche B, van Dyck D, Verloigne M, de Bourdeaudhuij I. Perceived social and physical environmental correlates of physical activity in older adolescents and the moderating effect of self-efficacy. Preventive Medicine. 2010;50:24-9. https://doi.org/10.1016/j.ypmed.2009.08.017.

17. Telama R. Tracking of physical activity from childhood to adulthood: A review. Obes Facts. 2009;2:187-95. https://doi.org/10.1159/000222244.

18. Eime RM, Harvey J, Charity M. Sport participation settings: where and 'how' do Australians play sport? BMC Public Health. 2020;20:1344. https:// doi.org/10.1186/s12889-020-09453-3.

19. Eime RM, Harvey JT, Sawyer NA, Craike MJ, Symons CM, Polman RCJ, et al. Understanding the contexts of adolescent female participation in sport and physical activity. Research Quarterly for Exercise and Sport. 2013;84:157-66. https://doi.org/10.1080/02701367.2013.784846.

20. Eime RM, Harvey JT, Sawyer NA, Craike MJ, Symons CM, Payne WR. Changes in sport and physical activity participation for adolescent females: a longitudinal study. BMC Public Health. 2016;16:533. https://doi. org/10.1186/s12889-016-3203-x.

21. Eime RM, Payne WR, Casey MM, Harvey JT. Transition in participation in sport and unstructured physical activity for rural living adolescent girls. Health Education Research. 2010;25:282-93. https://doi.org/10.1093/her/ cyn060.

22. Bergman $L R$, Lundh $L-G$. Introduction. The person-oriented approach: roots and roads to the future. Journal for Person-Oriented Research. 2015;1:1-6. 10.17505/jpor.2015.01.

23. Bergman $L R$, Magnusson D. A person-oriented approach in research on developmental psychopathology. Development and Psychopathology. 1997;9:291-319.

24. Lawler M, Heary C, Nixon E. Variations in adolescents' motivational characteristics across gender and physical activity patterns: a latent class analysis approach. BMC Public Health. 2017;17:661-74. https://doi.org/10. 1186/s12889-017-4677-x.

25. Borgers J, Thibaut E, Vandermeerschen H, Vanreusel B, Vos S, Scheerder J. Sports participation styles revisited: A time-trend study in Belgium from the 1970s to the 2000s. International Review for the Sociology of Sport. 2015;50:45-63. https://doi.org/10.1177/1012690212470823.

26. Scheerder J, Vanreusel B, Taks M. Leisure-time sport among physical education students: a time trend analysis of sport participation styles. European Sport Management Quarterly. 2005;5:415-41. https://doi.org/ 10.1080/16184740500430306.

27. Gut V, Schmid J, Conzelmann A. The interaction of behavioral context and motivational-volitional factors for exercise and sport in adolescence: patterns matter. BMC Public Health. 2020;20:685. https://doi.org/10.1186/ s12889-020-08617-5.

28. Bergman LR, Magnusson D, El-Khouri BM. Studying individual development in an inter-individual context. In: A person-oriented approach. Mahwah, NJ: Erlbaum; 2003

29. Dohrenwend BP. The role of adversity and stress in psychopathology: Some evidence and its implications for theory and research. Journal of Health and Social Behavior. 2000;41:1-19.

30. Schwarzer R, Luszczynska A. Stressful life events. In: Weiner IB, editor. Handbook of psychology: health psychology. 2nd ed. New York: John Wiley \& Sons; 2012. p. 29-56.

31. Khan A, Brown WJ, Burton NW. What physical activity contexts do adults with psychological distress prefer? Journal of Science and Medicine in Sport. 2013;16:417-21. https://doi.org/10.1016/j.jsams.2012.10.007.
32. Fuchs R, Klaperski S, Gerber M, Seelig H. Messung der Bewegungs- und Sportaktivität mit dem BSA-Fragebogen: Eine methodische Zwischenbilanz. [Measurement of physical activity and sport activity with the BSA questionnaire]. Zeitschrift für Gesundheitspsychologie. 2015;23:60-76. https://doi.org/10.1026/0943-8149/a000137.

33. Siegrist J, Geyer S. Inventar lebensverändernder Ereignisse. In: Danner D, Glöckner-Rist A, editors. Zusammenstellung sozialwissenschaftlicher Items und Skalen. Mannheim: GESIS; 2014. https://doi.org/10.6102/zis92.

34. Geyer S, Broer M, Haltenhof H, Bühler K-E, Merschbächer U. The evaluation of life event data. Journal of Psychosomatic Research. 1994;38:82335. https://doi.org/10.1016/0022-3999(94)90070-1.

35. Masyn KE. Latent class analysis and finite mixture modeling. In: Little TD, editor. The Oxford handbook of quantitative methods in psychology, Statistical analysis, vol. 2. New York, NY: Oxford University Press; 2013. p. 551-611. https://doi.org/10.1093/oxfordhb/9780199934898.013.0025.

36. Muthén LK, Muthén BO. Mplus user's guide. 8th ed. Los Angeles, CA; 1998-2017.

37. Morin AJS, Wang JCK. A gentle introduction to mixture modeling using physical fitness performance data. In: Ntoumanis N, Myers ND, editors. An introduction to intermediate and advanced statistical analyses for sport and exercise scientists. London, UK: Wiley; 2016. p. 183-210.

38. Bakk Z, Vermunt JK. Robustness of stepwise latent class modeling with continuous distal outcomes. Structural Equation Modeling: a Multidisciplinary Journal. 2016;23:20-31. https://doi.org/10.1080/10705511.2014. 955104.

39. Bryant FB, Satorra A. Principles and practice of scaled difference chisquare testing. Structural Equation Modeling: a Multidisciplinary Journal. 2012;19:372-98. https://doi.org/10.1080/10705511.2012.687671.

40. Borgers J, Seghers J, Scheerder J. Dropping out from clubs, dropping in to sport light? In: Green K, Smith A, editors. Routledge handbook of youth sport. New York, NY: Routledge; 2016. p. 158-74.

41. Stults-Kolehmainen MA, Sinha R. The effects of stress on physical activity and exercise. Sports Medicine. 2014;44:81-121. https://doi.org/10.1007/ s40279-013-0090-5.

42. Lazarus RS, Folkman S. Stress, appraisal, and coping. New York, NY: Springer; 2006

43. Bergman $L R$, Wångby $M$. The person-oriented approach: A short theoretical and practical guide. Eesti Haridusteaduste Ajakiri. Estonian. Journal of Education. 2014;2(29-49). https://doi.org/10.12697/eha.2014.2.1.02b.

44. Gillison FB, Sebire SJ, Standage M. What motivates girls to take up exercise during adolescence? Learning from those who succeed. British Journal of Health Psychology. 2012;17:536-50. https://doi.org/10.1111/j. 2044-8287.2011.02053.x.

\section{Publisher's Note}

Springer Nature remains neutral with regard to jurisdictional claims in published maps and institutional affiliations.

Ready to submit your research? Choose BMC and benefit from:

- fast, convenient online submission

- thorough peer review by experienced researchers in your field

- rapid publication on acceptance

- support for research data, including large and complex data types

- gold Open Access which fosters wider collaboration and increased citations

- maximum visibility for your research: over $100 \mathrm{M}$ website views per year

At BMC, research is always in progress.

Learn more biomedcentral.com/submissions 